\title{
Formação Matemática de Professores dos Anos Iniciais
}

\section{Rosana de Oliveira}

Universidade do Estado do Rio de Janeiro (EDU/UERJ)

rosanaol40@yahoo.com.br

\section{Nádia Estelino Ferraz}

Universidade do Estado do Rio de Janeiro (EDU/UERJ)

nadiaeferraz@hotmail.com

\section{Resumo}

Esse texto tem por objetivo apresentar um relatório sobre o III Seminário em Educação Matemática: Formação de Professores nos Anos Iniciais, evento realizado pelo GEPEM em parceria com o Projeto de Extensão: Formação de Professores e Divulgação Científica em Educação Matemática da Faculdade de Educação da Universidade do Estado do Rio de Janeiro em junho de 2017.

Palavras-chave: Anos iniciais. GEPEM. Formação de Professores. Educação Matemática.

\section{Mathematics Training form Elementary School Teachers}

\begin{abstract}
This text aims to present a report of the 3rd Seminar on Mathematics Education: Teacher Training in the Elementary Education an event held by GEPEM (Mathematics Education Study and Research Group") in partnership with the Extension Project: Teacher Training and Scientific Divulgation in Mathematics Education of the College of Education of the Rio de Janeiro State University in June 2017.
\end{abstract}

Keywords: Elementary Education. GEPEM.Teacher Education. Mathematics Education.

\section{Introdução}

O GEPEM através de sua história contribuiu de forma significativa com a formação continuada de professores que ensinam matemática nos diferentes níveis da escolaridade, por meio da realização de eventos e cursos de extensão e de especialização (OLIVEIRA, ALVES E FERRAZ, 2016).

Atualmente essa formação continua acontecendo de forma mais ampla em termos de oferta com iniciativas das Universidades, seja através de seus grupos de estudos e pesquisas, e também com atividades de extensão. Nessa perspectiva se insere o Projeto de Extensão "Formação de 
Professores e Divulgação Cientifica em Educação Matemática" (EDU/UERJ) que tem promovido diferentes ações periodicamente desde a sua origem (2014), promovendo alguns eventos em parceria com o GEPEM. Na realização o III Seminário em Educação Matemática, elegemos como foco a formação matemática dos professores dos anos iniciais do Ensino Fundamental.

A seguir apresentamos uma tabela com os eventos realizados pelo Projeto de Extensão "Formação de Professores e Divulgação Cientifica em Educação Matemática" (EDU/UERJ), identificando aqueles em parceria com o GEPEM.

Quadro 1 - Eventos e cursos realizados pelo Projeto de Extensão: Formação de Professores e Divulgação Cientifica em Educação Matemática

\begin{tabular}{|c|c|c|c|}
\hline Eventos & Ano & $\begin{array}{l}\text { Carga } \\
\text { Horária }\end{array}$ & $\begin{array}{l}\text { Parceria } \\
\text { com } \\
\text { GEPEM }\end{array}$ \\
\hline I Feira Interativa de Educação Matemática & 2014 & $12 \mathrm{~h}$ & \\
\hline $\begin{array}{l}\text { I Seminário em Educação Matemática: Formação de } \\
\text { Professores }\end{array}$ & 2015 & $6 \mathrm{~h}$ & $\mathrm{X}$ \\
\hline II Feira Interativa de Educação Matemática & 2015 & $12 \mathrm{~h}$ & \\
\hline $\begin{array}{l}\text { I Mostra Interativa em Educação Matemática: "quem sabe } \\
\text { faz a hora não espera acontecer" }\end{array}$ & 2016 & $4 \mathrm{~h}$ & \\
\hline $\begin{array}{l}\text { II Seminário em Educação Matemática: Formação de } \\
\text { Professores - Comemoração dos } 40 \text { anos do GEPEM }\end{array}$ & 2016 & $9 \mathrm{~h}$ & $\mathrm{X}$ \\
\hline III Feira Interativa de Educação Matemática & 2016 & $12 \mathrm{~h}$ & \\
\hline $\begin{array}{l}\text { Curso - Educação Matemática: sistema de numeração com } \\
\text { uso de materiais manipuláveis. }\end{array}$ & 2017 & $20 \mathrm{~h}$ & \\
\hline $\begin{array}{l}\text { III Seminário em Educação Matemática: Formação de } \\
\text { Professores dos Anos Iniciais }\end{array}$ & 2017 & $6 \mathrm{~h}$ & $\mathrm{X}$ \\
\hline $\begin{array}{l}\text { A construção do número, o sistema de numeração decimal e } \\
\text { as operações básicas: propostas de atividades (Minicurso na } \\
\text { Escola SESI de Jacarepaguá) }\end{array}$ & 2017 & $4 \mathrm{~h}$ & \\
\hline $\begin{array}{l}\text { Laboratório Interativo em Educação Matemática (Oficina na } \\
\text { Semana Paulo Freire CA/EDU-UERJ) }\end{array}$ & 2017 & $2 \mathrm{~h}$ & \\
\hline $\begin{array}{l}\text { IV Seminário em Educação Matemática: Reorganização } \\
\text { Curricular nos Anos Iniciais e Educação Infantil. }\end{array}$ & 2017 & $24 \mathrm{~h}$ & \\
\hline
\end{tabular}

Fonte elaborado pelas autoras.

\section{Seminário em Educação Matemática: Formação de Professores dos Anos Iniciais}

O III Seminário em Educação Matemática - Formação de Professores dos Anos Iniciais - realizouse no dia 22 de junho de 2017, nas dependências da Faculdade de Educação da Universidade do Estado do Rio de Janeiro (UERJ) - Campus Maracanã. O evento foi gratuito e contou com cerca de 132 inscritos, dos quais 100 compareceram. Foram oferecidos quatro minicursos, no turno da tarde. 
Ao final do dia realizamos uma palestra voltada para a prática pedagógica. O quadro a seguir descreve os títulos dos minicursos, da palestra e os respectivos ministrantes e suas instituições.

Quadro 2 - Atividades do III Seminário em Educação Matemática:

Formação de Professores dos Anos Iniciais

\begin{tabular}{|c|c|c|}
\hline \multicolumn{3}{|c|}{ PALESTRA } \\
\hline & $\begin{array}{l}\text { EDUCAÇÃO MATEMÁTICA E FESTA INFANTIL: } \\
\text { UMA RELAÇÃO POSSÍVEL }\end{array}$ & $\begin{array}{l}\text { Luana Amarolli Queiroz - Colégio } \\
\text { Pedro II }\end{array}$ \\
\hline \multicolumn{3}{|c|}{ MINICURSOS } \\
\hline & Título & Ministrantes/Instituições \\
\hline 1 & $\begin{array}{l}\text { CIRCUITO DE DADOS E CARTAS: ATIVIDADES } \\
\text { ENVOLVENDO ADIÇÃO E SUBTRAÇÃO }\end{array}$ & $\begin{array}{l}\text { Daiana Lino Souza Ribeiro da Silva - } \\
\text { PIBID/UFRRJ } \\
\text { Renan Tosta Santos - PIBID/UFRRJ } \\
\text { Dora Soraia Kindel - UFRRJ }\end{array}$ \\
\hline 2 & $\begin{array}{l}\text { DESCOMPLICANDO A GEOMETRIA NOS ANOS } \\
\text { INICIAIS }\end{array}$ & $\begin{array}{l}\text { Marcelo Bairral - UFRRJ } \\
\text { Soraya B. Izar - CPII/Cap-UERJ } \\
\text { Alunos de Ensino de Matemática II }\end{array}$ \\
\hline 3 & $\begin{array}{l}\text { ZOLTAN DIENES: JOGOS COM OS BLOCOS } \\
\text { LÓGICOS }\end{array}$ & $\begin{array}{l}\text { Denise Medina - EDU/UERJ } \\
\text { Rayssa Caetano - EDU/UERJ }\end{array}$ \\
\hline 4 & $\begin{array}{l}\text { PENSAMENTO ALGÉBRICO NOS ANOS INICIAIS } \\
\text { DO ENSINO FUNDAMENTAL }\end{array}$ & $\begin{array}{l}\text { Maria Isabel R. Ortigão } \\
\text { ProPEd/UERJ; } \\
\text { Maria José Costa dos Santos } \\
\text { ProPEd/Pós-doutoranda /UERJ }\end{array}$ \\
\hline
\end{tabular}

Fonte elaborado pelas autoras.

A seguir apresentamos um breve resumo das atividades realizadas ilustradas com fotos.

Palestra - Educação matemática e festa infantil: uma relação possível

$\mathrm{Na}$ Educação Infantil é preciso utilizar os momentos cotidianos para planejá-los com foco pedagógico. Dessa forma, relacionar a aprendizagem de conceitos e conteúdos matemáticos com as festas organizadas na escola foi objeto de atividades muito promissoras. As crianças participam de todo o processo de organização da festa, vivenciando experiências do contexto numérico e geométrico. 
Figura 01 - Foto da Palestra: A Profa ${ }^{\text {a }}$ Rosana de Oliveira apresenta aos participantes a Prof ${ }^{\text {a }}$ Luana Amarolli Queiroz, ministrante da palestra.

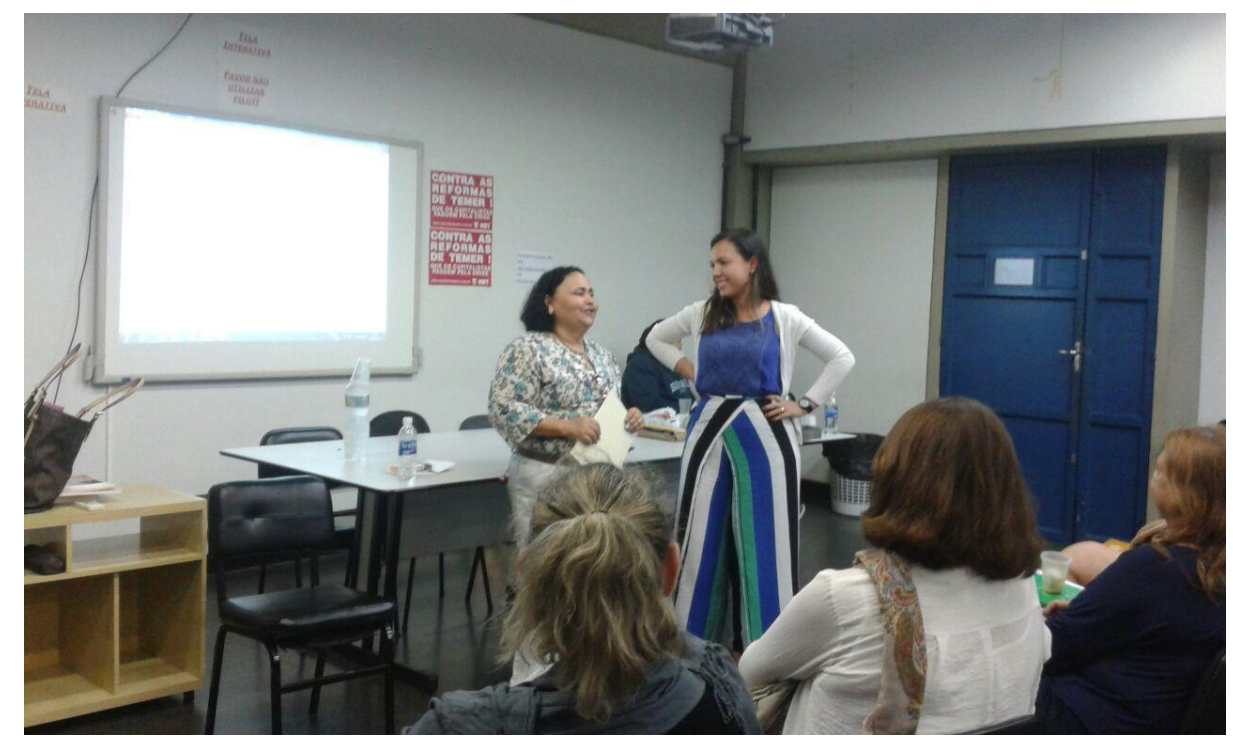

Minicurso 1 - Circuito de dados e cartas: atividades envolvendo adição e subtração

O circuito é formado por 10 atividades lúdicas envolvendo operações de adição ou subtração, usando dados ou baralhos. A principal ideia é propor aos participantes do minicurso a possibilidade de vivenciar os jogos e, a partir deles, refletir sobre o uso de materiais manipuláveis em sala de aula.

Figura 02 - Foto do Minicurso 1: A prof ${ }^{\text {a }}$ Soraia Kindel e Renan Tosta interagem com os participantes em uma das tarefas propostas no circuito.

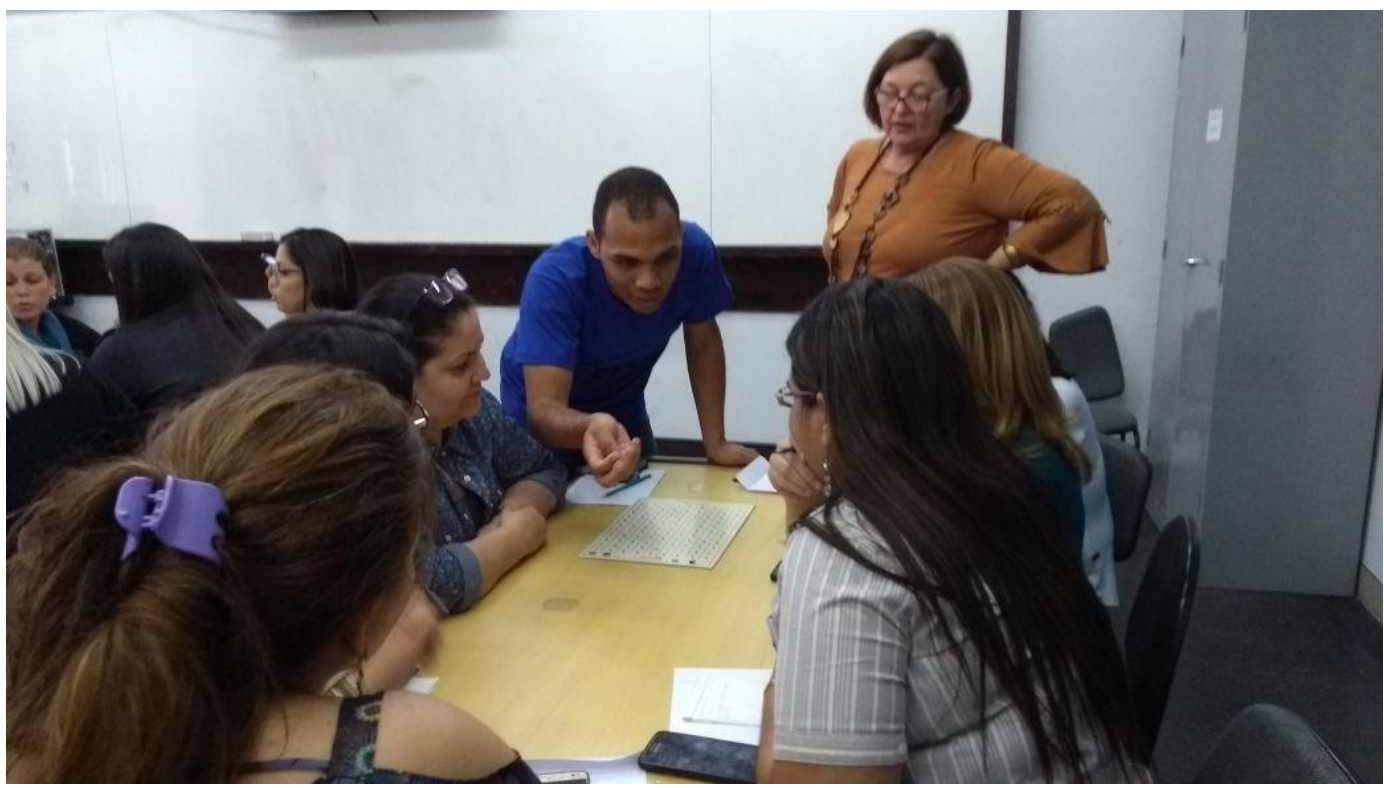


Figura 03 - Foto do Minicurso 1: A profa . Soraia Kindel, Renan Tosta e Daiana Lino dinamizam os pequenos grupos em que a turma foi dividida.

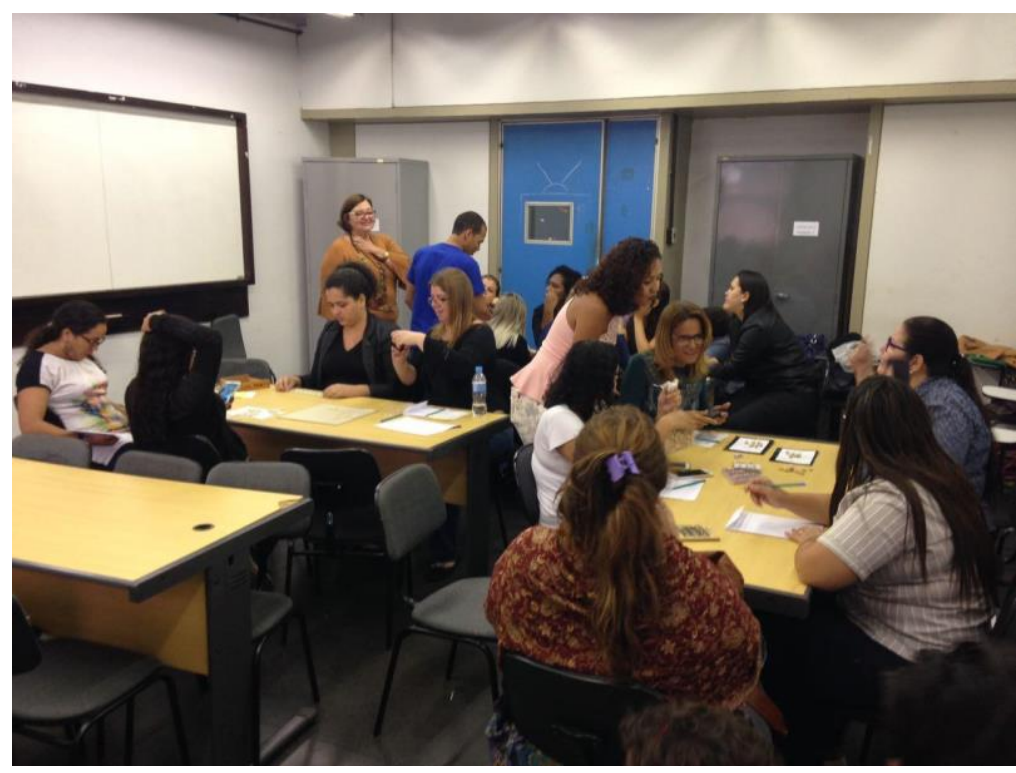

Minicurso 2 - Descomplicando a geometria nos anos iniciais

Desenvolver conceitos a partir de diferentes recursos e da própria reflexão em aula deve ser um dos propósitos nas diferentes séries. Nessa oficina, mediante um circuito de atividades com o uso de diferentes materiais, oportunizamos aos participantes vivenciar e discutir com o coletivo o seu aprendizado sobre formas geométricas nos anos iniciais. Além disso, o cursista pode experimentar uma atividade com o celular.

Figura 4 - Foto do Minicurso 2: Prof. Marcelo Bairral introduz atividades de simetria com espelhos.

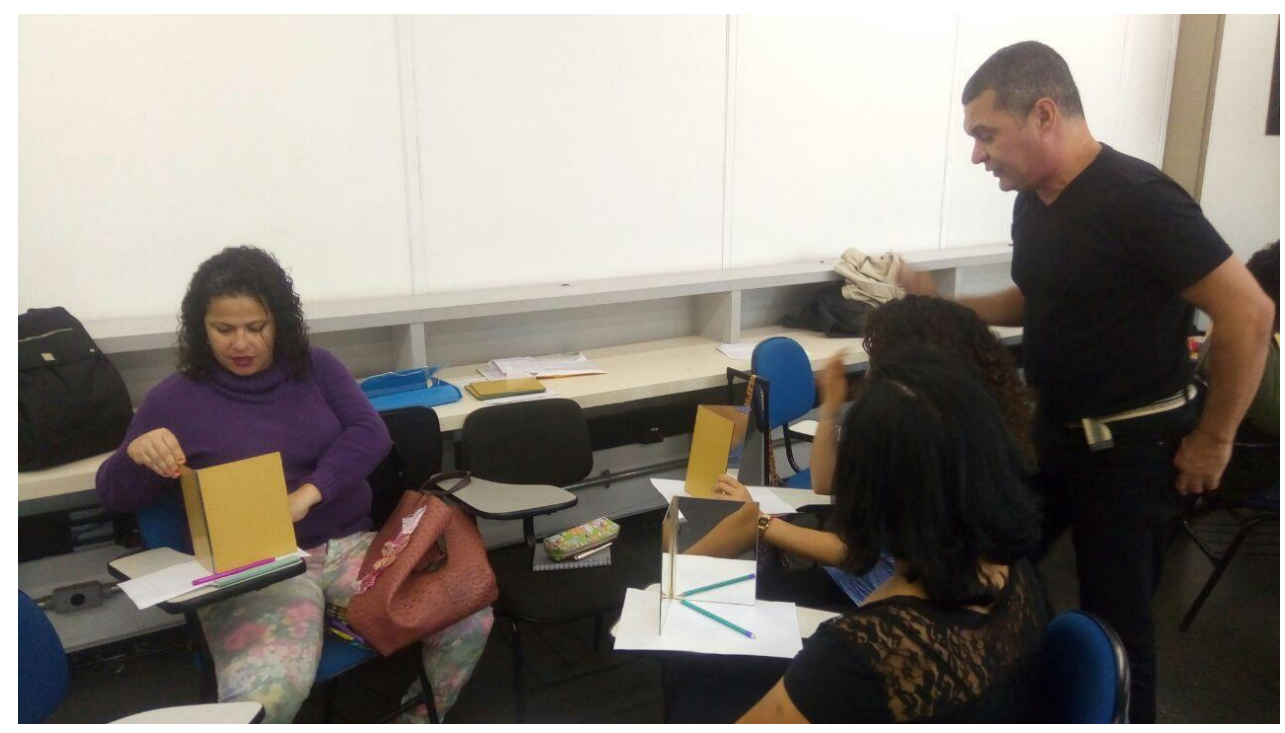


Figura 5 - Foto do Minicurso 2: Os participantes inseridos nas atividades propostas sendo observados pelos professores Marcelo Bairral, Soraya Izar e os licenciandos de Matemática da UFRRJ.

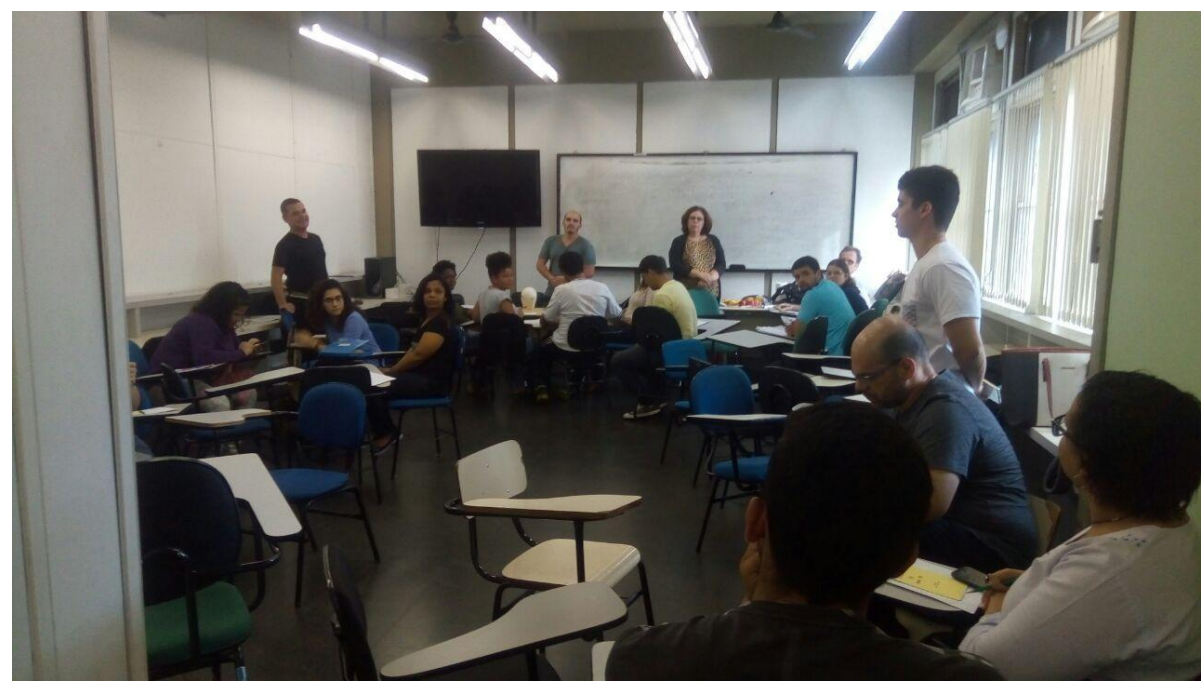

\section{Minicurso 3 - Zoltan Dienes: Jogos com os Blocos Lógicos}

O objetivo do minicurso é apresentar os Blocos Lógicos, também conhecidos como Blocos Lógicos de Dienes, pois foram idealizados pelo matemático húngaro Zoltan Paul Dienes. Esse material tradicionalmente era feito em madeira, mas hoje pode ser encontrado em plástico ou emborrachado. Além disso, pode ser confeccionado em isopor ou papel cartão (ou outro similar que dê rigidez para poder ser manipulado). Vamos explorar o material para entendermos sua estrutura. E a partir desse reconhecimento, propor atividades que envolvem ações de agrupar, classificar e estabelecer correspondências entre as peças, além de identificar semelhanças, diferenças e construir sequências lógicas.

Figura 06 - Foto do Minicurso 3: A Prof ${ }^{\mathrm{a}}$. Denise Medina apresenta o material para os participantes.

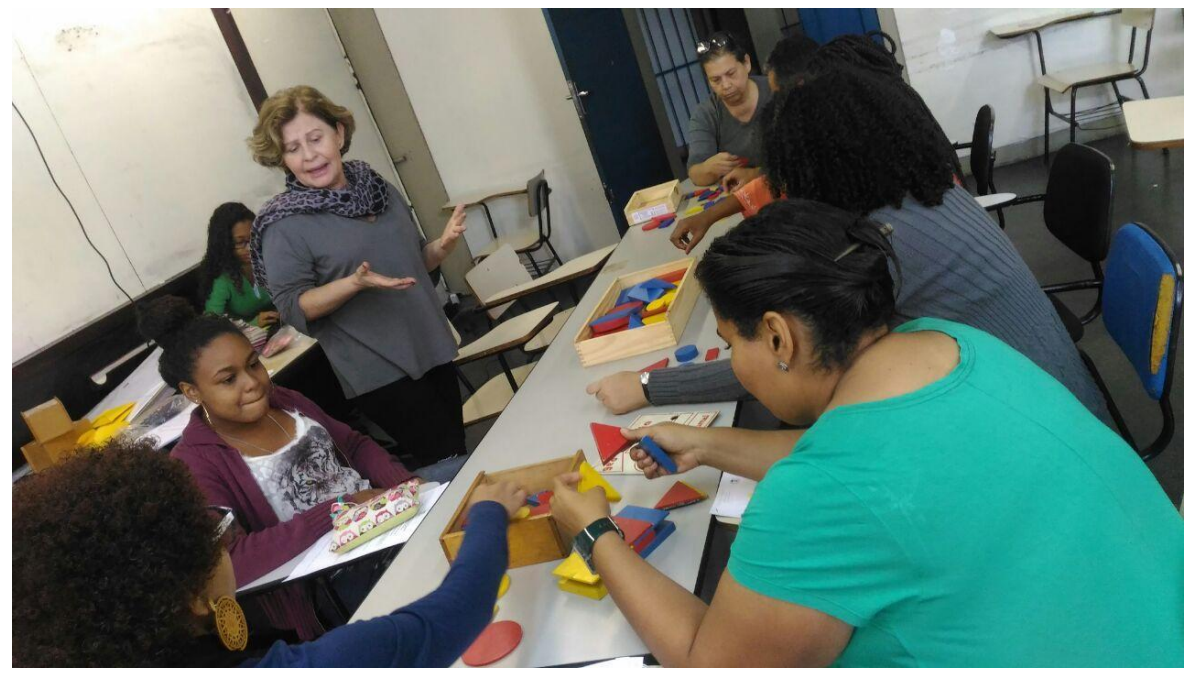


Figura 07 - Foto do Minicurso 3: Participantes observam e fazem anotações sobre as características do material, atividade proposta pela Prof ${ }^{\mathrm{a}}$. Denise Medina.

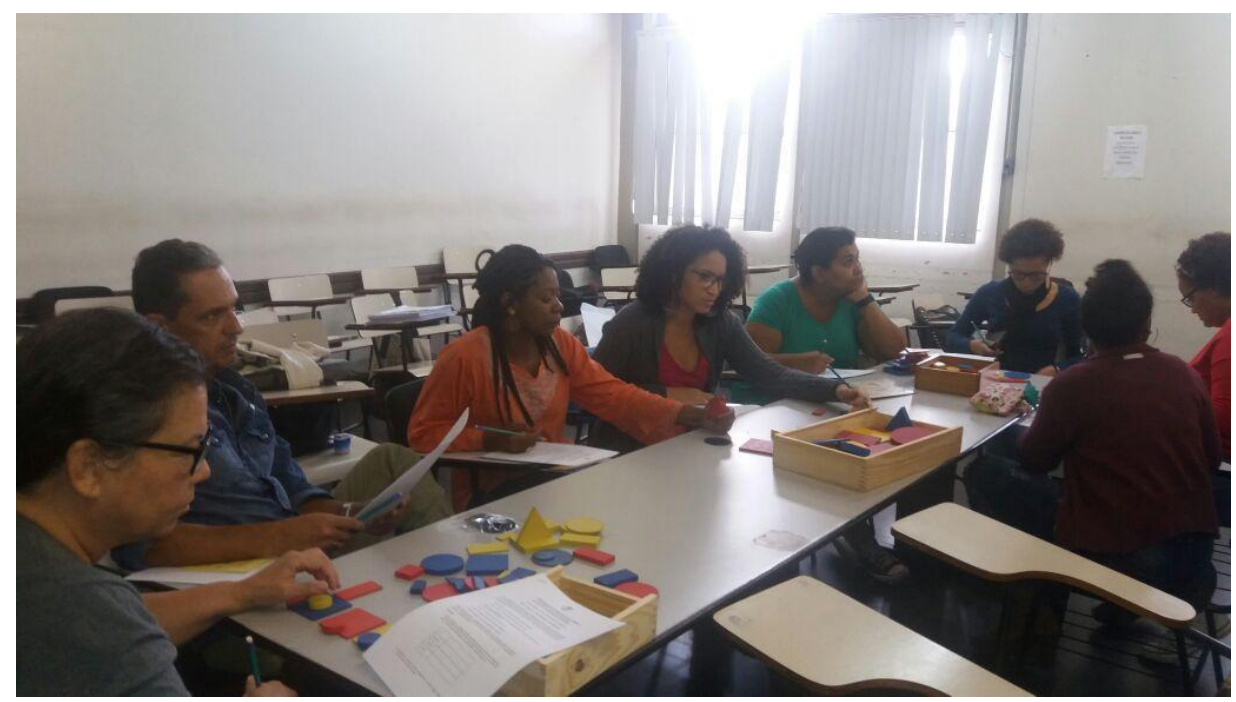

\section{Minicurso 4 - Pensamento algébrico nos anos iniciais do Ensino Fundamental}

O estudo de temas algébricos nos anos iniciais do Ensino Fundamental envolve não o trabalho com símbolos, mas a identificação de regularidades em sequências numéricas, de figuras ou de outro tipo. O estudo de regularidades nesta etapa inicial de escolaridade pode ser feito por meio da proposição de atividades que, dentre outros aspectos, conduzam o estudante a identificar os elementos e as regras de formação dessas sequências. Tal trabalho pode ser articulado ao estudo dos números e das figuras geométricas, por exemplo. O objetivo deste minicurso é o de contribuir para a formação inicial de professores, promovendo uma discussão sobre o trabalho com regularidades nos anos iniciais.

Figura 8 - Foto do Minicurso 4: Professoras Isabel Ortigão e Maria José Costa com os participantes posam para foto ao final do minicurso.

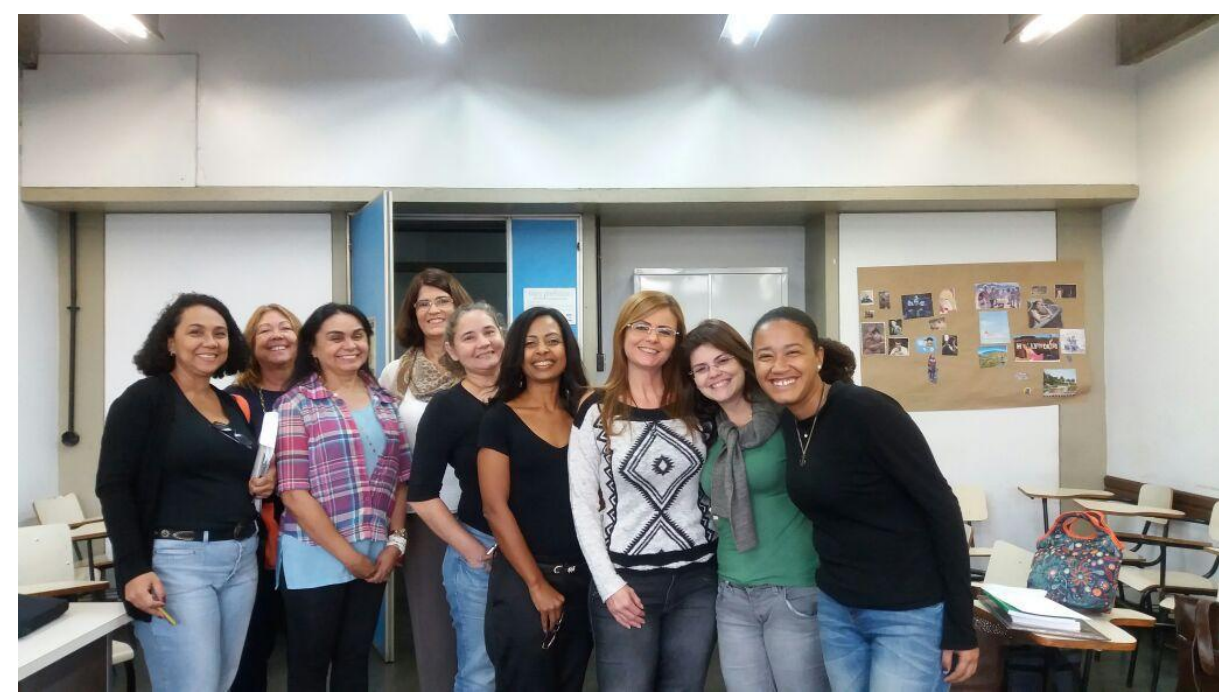


Figura 09 - Foto do Minicurso 4: Participantes envolvidos com as atividades promovidas no minicurso sobre o pensamento algébrico.

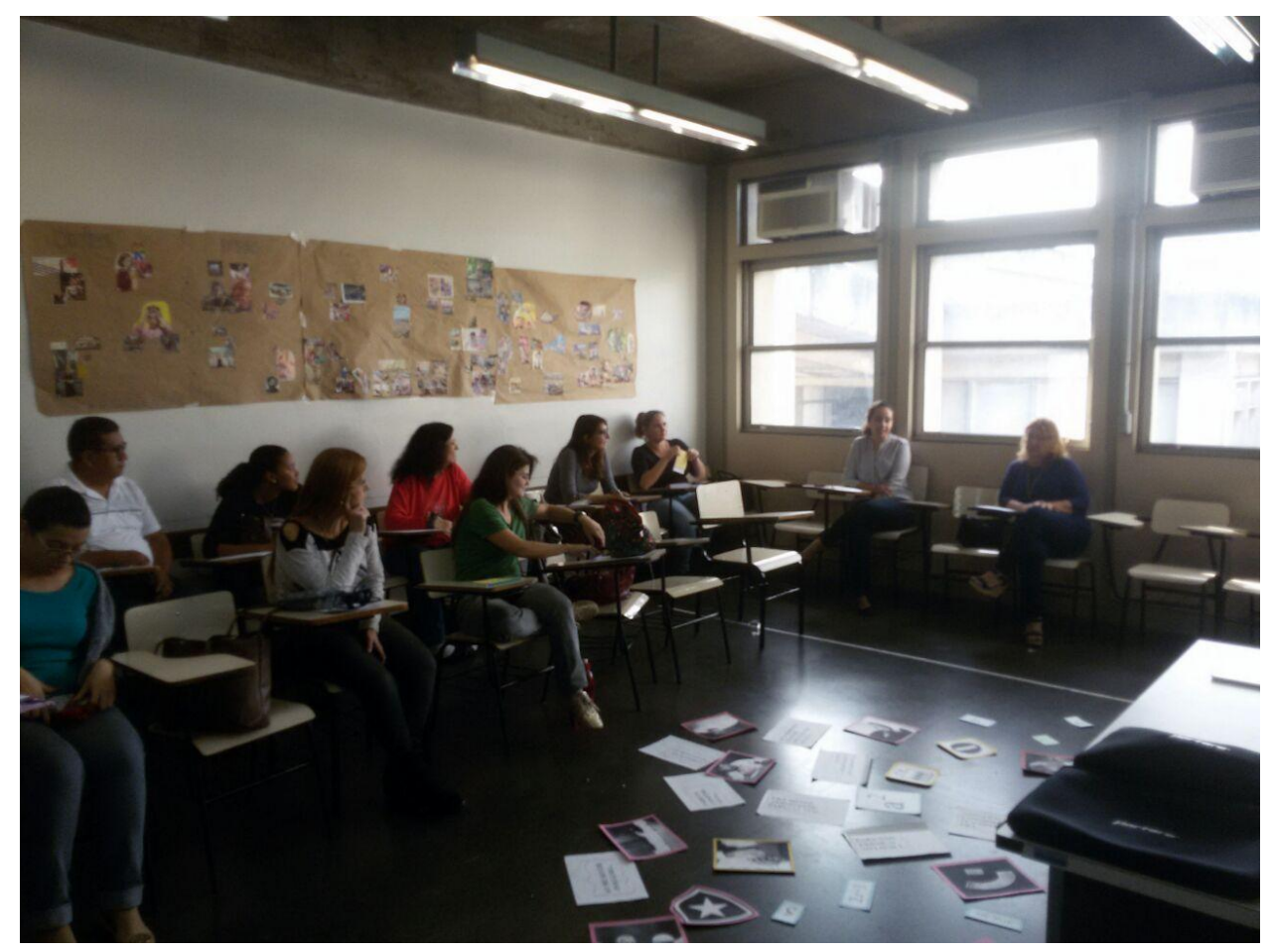

\section{A utilização de materiais manipuláveis, jogos e vivências na formação continuada de professores}

Com objetivo de produzir sentidos e significados para o ensino de Matemática nos anos iniciais e na educação infantil acreditamos que as práticas pedagógicas devem estar impregnadas de propostas que envolvam materiais manipuláveis, jogos, vivências de situações relacionadas aos conteúdos e a conceitos matemáticos. A utilização de apenas um desses recursos não garante a aprendizagem. "A diversidade de oferta de materiais é o que possibilita a construção de conceitos mais avançados pelos estudantes" (KINDEL; OLIVEIRA, 2016, p. 69). Além disso, é preciso estimular o debate, o registro, a leitura, a elaboração de perguntas e argumentos, a comunicação matemática, a visualização e a observação. Dessa forma, as atividades promovidas nos minicursos e a palestra do III Seminário em Educação Matemática - Formação de Professores dos Anos Iniciais - atenderam a essa expectativa. Exploramos as operações básicas com 10 jogos e atividades (Minicurso 1), os agrupamentos, classificações, semelhanças e diferenças utilizando os blocos lógicos e outros materiais similares (Minicurso 2), o contexto geométrico (Minicurso 3), e o pensamento algébrico no estudo de sequências e generalizações (Minicurso 4).

Existe uma crença por parte de grande parte de professores dos anos iniciais e da educação infantil que atividades lúdicas, em particular em matemática, resolvem dificuldades de 
aprendizagem nessa disciplina. A ludicidade de maneira geral disponibiliza o estudante para a aprendizagem, mas não garante o êxito. O prazer de vivenciar uma proposta lúdica não implica em aprendizagens. É preciso promover outras ações após a vivência de uma proposta como, por exemplo, revisitar sob outros aspectos aquele conceito, solicitar que o aprendiz crie outra atividade, reflita e fale sobre o que aprendeu ou observou. Ao professor cabe uma escuta cuidadosa e intervenções que contribuam para a produção de significados.

Celebramos a parceria da Faculdade de Educação com o GEPEM, acreditando que o investimento e disponibilidade em atuar na formação matemática de professores inicial e continuada devem ser permanentes. Reiteramos, assim, o papel de resistência das Universidades Públicas, em particular aquelas envolvidas nesse evento, Universidade Federal Rural do Rio de Janeiro (UFRRJ) e Universidade do Estado do Rio de Janeiro (UERJ) que segue, apesar do "desgoverno", promovendo e desenvolvendo suas atividades de ensino, pesquisa e extensão, tão necessárias nos tempos atuais.

\section{Referências}

KINDEL, D. S; OLIVEIRA, R. O Uso de Materiais Manipuláveis na Alfabetização Matemática. In: MAIS, M. G. B; BRIÃO, G (Org). Alfabetização Matemática: Perspectivas Atuais. 1. ed. Curitiba: CRV, 2017. Cap. 4, p. 61-81. V. 1.

OLIVEIRA, R., ALVES, N.F., e FERRAZ, N.E. O GEPEM e a Formação de Professores: 40 Anos de Atuação. Boletim GEPEM, Rio de Janeiro, n. 68, p. 92-102, 2016. 